\title{
Spontaneus pregnancy after obstructive nabothian cyst treatment
}

\section{Gökçe Turan*, Pınar Yalçın Bahat, Berna Aslan Çetin}

\begin{abstract}
Department of Obstetrics and Gynecoloy, Istanbul Kanuni Sultan Suleyman Training and Research Hospital, Istanbul,
\end{abstract} Turkey

Received: 26 February 2017

Revised: 28 April 2017

Accepted: 01 May 2017

\section{*Correspondence:}

Dr. Pınar Yalçın Bahat,

E-mail: dr_pinaryalcin@hotmail.com

Copyright: (c) the author(s), publisher and licensee Medip Academy. This is an open-access article distributed under the terms of the Creative Commons Attribution Non-Commercial License, which permits unrestricted non-commercial use, distribution, and reproduction in any medium, provided the original work is properly cited.

\section{ABSTRACT}

Nabothian cysts are common and silent retention cysts of the uterine cervix with no particular intervention required. It is quite rare to reach a size of more than $4 \mathrm{~cm}$ and it is a diagnostic dilemma to differ it from adenoma malignum. Here we report a case a woman who conceived after $3.5 \mathrm{~cm}$ of naboth cyst treatment.

Keywords: Excision, Naboth cyst, Pregnancy

\section{INTRODUCTION}

Nabothian cysts are common gynecologic findings and rarely of clinical significance. ${ }^{1-3}$ Nabothian cysts are formed when a gland of cervix which is fitted by the columnar epithelium covered with squamous cells and the columnar cells continue to secrete mucoid material. Nabothian cysts may occur by the inflammation and reperative processes of chronic cervicitis, following minor trauma or childbirth. ${ }^{4}$ Submucosal layer of the cervix is the most common location of these cysts, rarely they are seen deeply into the cervical wall. Anechoic cystic structures are the ultrasonographic apperances of these cysts. Here we report a case a woman who conceived after $3.5 \mathrm{~cm}$ of naboth cyst treatment. ${ }^{5}$

\section{CASE REPORT}

A 32 year-old women, G1, P1 has a normal birth and married for six years. She was admitted to our clinic with infertility.

A 1.5-year-old unprotected patient has a 4-year-old child. In her past medical history is clear. General examination of the patient showed no abnormalities. The speculum examination revealed a multiparous enlarged cervix with an appearance a naboyhian cyst approximately 3.5 centimeters, completely closed the entrance of the collum.

Transvaginal ultrasonography showed normal ovaries and the endometrial thickness was $6 \mathrm{~mm}$. Pap smear test was performed and no pathology was detected.

There was no abnormality in the laboratory tests including hormone profile, anti müllerian hormone was 3.2. Her husband's semen analysis was normal. Cervical dilatation was applied to the patient for treatment. Antibiotic treatment started. The patient was discharged on the same day, regular sexual intercourse was recommended. She was diagnosed to be pregnant spontaneously after a month's follow-up examination. At the time of writing, the patient had an ongoing pregnancy.

\section{DISCUSSION}

Nabothian cysts are the retention cysts in the uterine cervix. Nabothian cysts are common, nonneoplastic gynecologic disorder and rarely of clinical significance. ${ }^{6}$ 
Tunnel clusters and endocervical glandular hyperplasia are distinguished by histological diagnosis. Nabothian cysts are usually small spanning a few millimetres in diameter but on occasion, have been reported reach extreme sizes of up to $4 \mathrm{~cm}$. Deep nabothian cysts are uncommon nonneoplastic lesions of the cervix. ${ }^{7}$

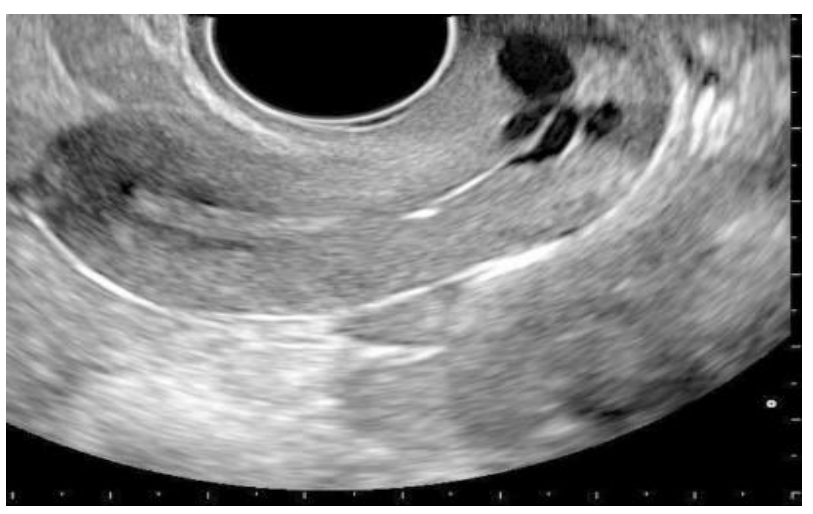

Figure 1: Big nabothian cyst (USG).

The squamocolumnar junction of the cervix is not a static tissue; the squamous epithelium of the uterine cervix proliferates and covers the columnar epithelium of the endocervical glands. Nabothian cysts formed when a cleft of columnar epithelium becomes covered with squamous cells and the columnar cells continue to secrete mucoid material (Figure 3).

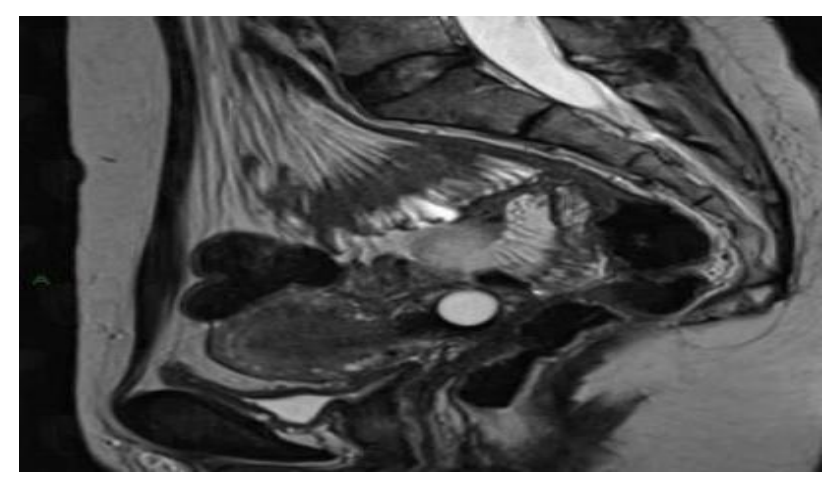

Figure 2: Big nabothian cyst (MRI).

Transvaginal ultrasonography (Figure 1) and magnetic resonance imaging (MRI) are the most useful imaging modalities for cervical cystic lesions. Typically seen an anechoic well defined cystic lesion near the endocervical canal. If the cysts are large, the cervical region can appear enlarged. ${ }^{8}$ Colour Doppler interrogation shows no associated colour flow. They are common and some reports suggest that they may be seen in up to $12 \%$ of routine pelvic MRI scans (Figure 2).

Generally, nabothian cysts do not require any therapy. If the lesion character is not clear and malignancy cannot be ruled out and if the patient relief from pain or a bothersome feeling of fullness in the vagina surgical intervention is needed. Ablation of the cyst using electrocautery is the usual approach; however, if the diagnosis is uncertain, excision to evaluate histopathology is advised. ${ }^{9}$ The main disadvantage to surgical treatment is the possibility of causing scar tissue, which itself can lead to dyspareunia. Despite the use of these contemporary diagnostic approaches, exploratory laparotomy and hysterectomy may still be needed in the case of unusually large and deep intracervical cysts, when malignancy cannot be excluded. ${ }^{10-11}$

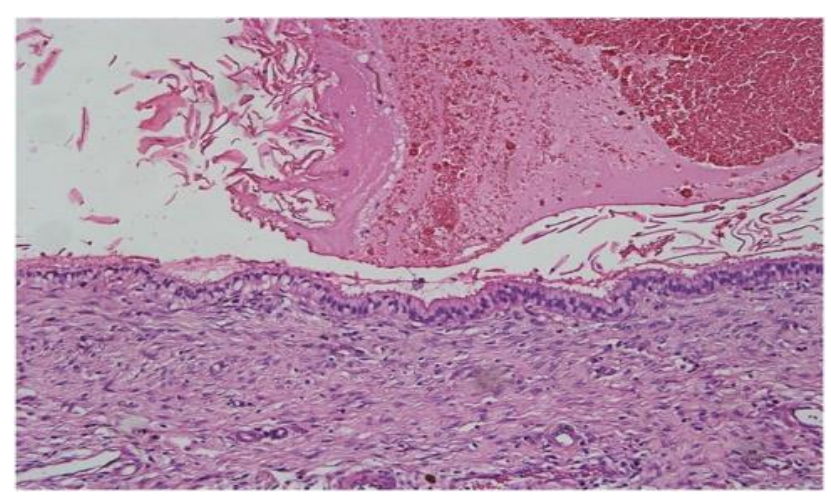

Figure 3: The ciliated columnar epithelium without atypia ( $\mathrm{H}$ and $\mathrm{E}, \mathbf{2 0 0 X})$.

\section{CONCLUSION}

In conclusion, despite nabothian cysts are benign and common findings of gynecology practice, they may unusually present with giant mass. If the cystic mass in the cervix is large and deeply located total excision is required to exclude malignancy.

\section{Funding: No funding sources \\ Conflict of interest: None declared \\ Ethical approval: Not required}

\section{REFERENCES}

1. Sosnovski V, Barenboim R, Cohen HI, Bornstein J. Complex nabothian cysts: a diagnostic dilemma. Arch Gynecol Obstet. 2009;279:759-61.

2. Kier R. Non-ovarian gynecologic cysts: MR imaging findings. AJR Am J Roentgenol. 1992;158:1265-9.

3. Katz VL, Lobo RA, Lentz G, Gershenson D. Comprehensive Gynecology. $5^{\text {th }}$ Ed. Philadelphia, PA: Mosby/Elsevier; 2007:437-8.

4. Malpica A, Robboy SJ. Cervical Benign and Nonneoplastic conditions in: Robboy Pathology of Female Reproductive Tract. $2^{\text {nd }}$ Ed. Elsevier; 2009:141-66.

5. Nigam A, Choudhary D, Raghunandan C. Large nabothian cyst: a rare cause of nulliparous prolapse. Case Rep Obstet Gynecol. 2012;2012:192526.

6. Temur I, Ulker K, Sulu B, Karaca M, Aydin A, Gurcu B. A giant cervical nabothian cyst compressing the rectum, differential diagnosis and literature review. Clin Exp Obstet Gynecol. 2011;38(3):276-79. 
7. Clement PB, Young RH. Deep nabothian cysts of the uterine cervix. A possible source of confusion with minimal-deviation adenocarcinoma (Adenoma malignum). Int J Gynecol Pathol. 1989;8(4):340-8.

8. Sosnovski V, Barenboim R, Cohen HI, Bornstein J. Complex Nabothian cysts: a diagnostic dilemma. Arch Gynecol Obstet. 2009;279:759-61.

9. Ki EY, Byun SW, Park JS, Lee SJ, Hur SY. Adenoma malignum of the uterine cervix: report of four cases. World J Surg Oncol. 2013;11:168.

10. Temur I, Ulker K, Karaca M, Aydin A, Gurcu B. A giant cervical nabothian cyst compressing the rectum, differential diagnosis and literature review. Clin Exp Obstet Gynecol. 2011;38:276-9.

11. A Nigam, D Choudhary, C Raghunandan. Large nabothian cyst: a rare cause of nulliparous prolapses. Case report Obstet Gynecol. 2012:1925-6.

Cite this article as: Turan G, Bahat PY, Çetin BA. Spontaneus pregnancy after obstructive nabothian cyst treatment. Int J Reprod Contracept Obstet Gynecol 2017;6:2625-7. 